\section{Molecular characterization} of staphylococcal cassette chromosome mec and virulence encoding genes in methicillin-resistant staphylococci at a medical center in Lebanon

\section{Abstract}

Background: Methicillin-resistant staphylococci (MRS) are major human pathogens accounting for most hospital-acquired (HA) and community acquired (CA) infections worldwide. The recent increase inMRS in a medical center in Lebanon elicited the determination of SCCmec types, genotypes, and prevalence of Panton-Valentine leucociden (PVL) and toxic shock syndrome toxin-1 (TSST-1) among the MRS isolates.

Methods: Thirty-six MRS isolates collected between October 2010 and September 2011 at a medical center, Lebanon were typed using phenotypic and genotypic methods. Antimicrobial susceptibility was determined using the disk diffusion agar method. SCCmec typing was performed by multiplex PCR and sequence analysis. The prevalence of the genes encoding PVL and TSST-1 virulence factors and their transcription levels, were determined respectively by PCR and semiquantitative real-time PCR. The genomic relatedness of the isolates was assessed by random amplified polymorphic DNA (RAPD) analysis.

Results: Antimicrobial susceptibility revealed three distinct antibiotypes. The predominant SCCmec type found among the MRS isolates was type IVa (51\%). Twenty-nine percent harbored SCCmec type III and $14 \%$ harbored SCCmec type II. One isolate harbored SCCmec type IVc, and another harbored SCCmec type I. All methicillin-resistant Staphylococcus aureus (MRSA) isolates were negative for the gene encoding for $\mathrm{PVL}$, and two were positive for the gene encoding for TSST-1. RAPD analysis demonstrated high genomic diversity among the MRS isolates.
Mirna Rajeh, Ahmad Sabra,

Kohar Annie B. Kissoyan, Sukayna Fadlallah and Ghassan M. Matar

Department of Experimental Pathology, Immunology and Microbiology, Faculty of Medicine, American University of Beirut, Beirut, Lebanon

Corresponding author:

Prof. Dr. Ghassan M. Matar

झ gmatar@aub.edu.lb 
Conclusion: This study demonstrated the SCCmec types and the clonality of the MRS strains, allowing the differentiation between HA and CA-MRS strains. CA-MRS have increased in the hospital environment and rendered highly resistant to erythromycin and clindamycin.

Keywords: Staphylococcal Cassette, methicillin-resistant Staphylococcus aureus (MRSA), TSST-1

\section{Introduction}

Staphylococcus aureus is considered a leading cause of serious and sometimes life-threatening infections. S. aureus is frequently found on the skin, nasal and other mucous membranes of humans, and in various food products. In England in 1961, the first methicillin-resistant $S$. aureus (MRSA) was reported, only one year following the introduction of methicillin. Since then, MRSA has been recognized as a major cause of health-care associated infections. Recently, MRSA has emerged as an important community pathogen, and this was followed by the recognition of methicillin-resistant coagulase negative staphylococci (MRCNS) as important nosocomial pathogens $[1,2]$

A study by Tokajian S, 2014, showed that the local epidemiology within the Middle East (western Asia) region is fluctuating, owing to the introduction of new strains with the global exchange of several clones [3]. Another study performed by Shehabi et al. demonstrated the presence of 1-3 clinically important staphylococcal toxin genes more frequently colonizing Jordanian outtpatient infants[4]. Furthermore, another study by Nazeer A et al., 2012 retrieved 73 studies through PubMed using the search terms "methicillin-resistant S. aureus" (MRSA), and Saudi Arabia. They reported MRSA incidence or prevalence in patients and/or percentage among $S$. aureus isolates and evaluated these metrics against the closest matching SHEA (Society for Healthcare Epidemiology of America) /HICPAC (Healthcare Infection Control Practices Advisory Committee metrics) [5]

Methicillin resistance occurs in Staphylococcus species due to the expression of an altered penicillin-binding protein termed PBP2a or PBP2', that is encoded by the mecA gene [2] The mecA gene is located on a mobile staphylococcal cassette chromosome mec (SCCmec) element. This element exists in MRSA; as well as, MRCNS isolates. To date, at least five SCCmec (I-V) types have been described with sizes ranging between 21 to $67 \mathrm{~kb}$. The SCCmec types (I-V) have aided in the differentiation between hospital-acquired (HA) and community-acquired (CA) MRS strains. The larger Sccmec types (I-III) have been associated with HA infections; whereas, the smaller SCCmec types (IV and V) have been associated with CA infections[6-9].

SCCmec includes the mec gene complex which is comprised of the mecA gene and its regulators and the ccr gene complex that encodes site-specific recombinases. These recombinases are responsible for the mobility of the SCCmec[ 10].

Strains of $S$. aureus isolated from human sources can produce a variety of virulence factors. Panton- 
Valentine leucociden (PVL) is a pore-forming cytotoxin that is associated with severe skin and soft tissue infections and necrotizing pneumonia. PVL with SCCmec type IV is considered as a marker for CAMRSA infections; however, exceptions exist[11]. Another main virulence factor includes the toxic shock syndrome toxin-1 (TSST-1), which is a superantigen having a size of $29.1 \mathrm{kDa}$. TSST-1 is encoded by the tst gene. TSST-1 causes toxic shock syndrome (TSS), a severe and potentially fatal manifestation when it enters the bloodstream[12].

Infections due to hospital-acquired methicillin resistant staphylococci (HA-MRS) must be controlled otherwise they may become permanently present in a hospital environment. These endemic MRS are very challenging to overcome. In most cases, they increase the number of infections, lengthen the duration of hospital stay, and raise the amount of health-care costs. Since MRS strains are generally resistant to a broader range of antimicrobial agents, the chances of treatment become limited and the spectrum of antibiotic prescriptions changes. Therefore, the adequate identification of such resistant bacteria is a crucial and necessary obligation for the selection of the proper antimicrobial treatment as well as for the implementation of appropriate infection control measures [13].

In Lebanon and the Middle East there are numerous molecular characterization and epidemiological studies on MRSA especially during the last decade, highlighting their increased prevalence in the region [4,14-19]. However, there is scarce data available concerning the antibiotic susceptibility profiles, the SCCmec types and the genotypes of MRS strains that could be circulating in Lebanon.

Accordingly, the objective of this study was to perform phenotypic and genotypic characterization of MRS isolates from clinical specimens at a medical center in Lebanon.

\section{Materials and methods}

\section{Bacterial isolates, identification and confirmation of methicillin-resistance by phenotypic methods}

Thirty-six non-duplicated methicillin resistant staphylococci were isolated from clinical specimens (blood, pus, urine, bone, catheter, soft tissue, wound swabs, respiratory samples, and exudates) of in and out-patients at a medical center in Lebanon from October 2010 to September 2011. These isolates were identified as staphylococci based on their Gram stain, colonial morphology, as well as their catalase properties. Rapid agglutination and coagulase tests were done to distinguish between $S$. aureus and coagulase negative staphylococci (CNS). Methicillin resistance was confirmed using an oxacillin disk on Mueller-Hinton agar (Oxoid, England) according to Clinical and Laboratory Standards Institute (CLSI)guidelines[20].

\section{Antimicrobial susceptibility testing of staphylococcal isolates}

Antimicrobial susceptibility testing was performed by disk diffusion agar method on Mueller-Hinton agar against a panel of antimicrobial agents disks (Oxoid, England) according to CLSI guidelines[20].

\section{DNA extraction}

DNA was extracted from the staphylococcal isolates using illustra bacteria genomic Prep Mini Spin kit (GE Healthcare, UK) in accordance with the manufacturer's protocol for purification of genomic DNA from Gram-positive bacteria.

\section{Molecular characterization by multiplex PCR amplification and DNA sequencing}

Three multiplex PCR assays carried out using the PCR Sprint Thermal Cycler (Thermo Fisher Scientific, Waltham, MA, USA) were used for characterization of the methicillin-resistant staphylococcal isolates. 


\section{Polymerase Chain Reaction}

\section{SCCmec-typing Multiplex-PCR 1for typing and sub-typing of the SCCmec element with the simultaneous detection of the mecA gene}

The PCR mixture contained nine pairs of primers, specific for typing and sub-typing the SCCmec element; as well as, an internal control primer for confirming the presence of the mecA gene, were used in this multiplex polymerase chain reaction (M-PCR) assay. The various types and sub-types detected by the M-PCR included: I, II, III, IVa, IVb, IVc, IVd, and $V$. M-PCR was performed in a $25 \mu$ final reaction mixture with $5 \mu$ l of the prepared DNA template having a final concentration $10 \mu \mathrm{g} / \mathrm{ml}, 2.5 \mu \mathrm{l}$ of $10 \mathrm{x}$ Taq DNA polymerase buffer with $\mathrm{KCl}$ (Fermentas, USA), $2.5 \mu \mathrm{l}$ of $\mathrm{MgCl}_{2}$ (25mM) (Fermentas, USA), $0.2 \mu \mathrm{l}$ of Taq DNA polymerase $(5 \mathrm{U} / \mu \mathrm{l})$ (Fermentas, USA), $1 \mu$ of $5 \mathrm{mM}$ dNTPs (Fermentas, USA), 13.4 $\mu \mathrm{l}$ of nuclease free distilled water (Amresco, USA) and $0.2 \mu \mathrm{l}$ of each primer (Thermo Scientific Inc., USA)[13].

\section{Mec gene complexcharacterization M-PCR 2}

Two pairs of primers were used in this M-PCR assay to characterize the mec gene complex as either class A or B. The M-PCR was performed as described in 2.5.1 with thefollowing modification: $13.64 \mu \mathrm{l}$ of nuclease free distilled water (Amresco, USA) and $0.08 \mu \mathrm{l}$ of each primer, (Thermo Scientific Inc., USA)[13].

\section{Ccr gene complex characterization M-PCR 3}

Six primers were used in this M-PCR assay to characterize the ccr gene complex into four allotypes (types 1, 2, 3, and 5). The M-PCR was performed as described in 2.5.2

Amplification was performed using the same cycling conditions for all three sets of M-PCR reactions with denaturation at $94^{\circ} \mathrm{C}$ for 5 min; 35cycles of $94^{\circ} \mathrm{C}$ for $45 \mathrm{~s}, 56^{\circ} \mathrm{C}$ for $45 \mathrm{~s}$, and $72^{\circ} \mathrm{C}$ for $1.5 \mathrm{~min}$; and extension at $72^{\circ} \mathrm{C}$ for $10 \mathrm{~min}$.

\section{MRSA-PVL PCR.}

Was performedto detect the PVL toxin gene. The PCR was performed as described in Amplification was performed with denaturation at $94^{\circ} \mathrm{C}$ for 5 min; 35 cycles of $94^{\circ} \mathrm{C}$ for $10 \mathrm{~s}, 52^{\circ} \mathrm{C}$ for $20 \mathrm{~s}$, and $72^{\circ} \mathrm{C}$ for $40 \mathrm{~s}$; and extension at $72^{\circ} \mathrm{C}$ for $5 \mathrm{~min}$.

\section{Gel electrophoresis}

The amplicons from M-PCR1, 2, and 3 were separated on $2 \%$ agarose gels using a suitable DNA ladder; either, a 50 bp DNA ladder (Fermentas, USA) or a 123 DNA ladder (Sigma-Aldrich, USA). Gels were visualized under a UV transilluminator(Haakebuchler Instruments Inc, USA) and captured using Olympus digital camera, and the DigiDoc-ItProgram (UVP, UK). The amplicons were purified using the QIAquick Gel Extraction Kit (Qiagen, Valencia, California) and sequenced by the ABI 3100 genetic analyzer (Applied Biosystems, Foster City, CA,USA).

\section{RNA extraction\& reverse transcription}

RNA extraction was performed using the illustra RNAspin Mini RNA Isolation kit (GE healthcare, UK) for all MRSA isolates $(n=13)$. Subsequently, reverse transcription was performed using the QuantiTect ${ }^{\circledR}$ Reverse Transcription Kit (QIAGEN, Germany) to synthesize cDNA from the extracted RNA.

\section{Real Time Semi-Quantitative qRT- PCR}

qRT- PCRwas carried out using the Bio-Rad CFX96 Real Time System C1000 Thermal Cycler (Germany) to determine the transcription levels of the gene encoding TSST-1.The qRT-PCR was performed in a $20 \mu$ final reaction mixture with $10 \mu$ of QuatiFast SYBR Green PCR master mix, $4 \mu$ of RNase free $\mathrm{H}_{2} \mathrm{O}, 2 \mu \mathrm{l}$ of forward primer having a concentration of $5 \mu \mathrm{M}, 2 \mu \mathrm{l}$ of reverse primer having a concentration of $5 \mu \mathrm{M}$, and $2 \mu \mathrm{l}$ of synthesized cDNA. The 
following cycling conditions were used: denaturation at $94^{\circ} \mathrm{C}$ for $5 \mathrm{~min} ; 40$ cycles of $94^{\circ} \mathrm{C}$ for $10 \mathrm{~s}$, $56^{\circ} \mathrm{C}$ for $20 \mathrm{~s}$, and $72^{\circ} \mathrm{C}$ for $40 \mathrm{~s}$; and extension at $72^{\circ} \mathrm{C}$ for 5 min. Data analysis was performed using the Bio-Rad CFX Manager software (BioRad, USA).

\section{Random Amplified Polymorphic DNA analysis (RAPD)}

RAPD analysis was performed in order to detect the genomic polymorphisms of the thirty-six MRSA isolates. RAPD was done using the Ready-To-Go RAPD Analysis Beads kit (GE Healthcare, UK Limited) as specified by the manufacturer, using the PCR Sprint Thermal Cycler (Thermo Fisher Scientific, Waltham MA, USA).

\section{Results}

\section{Bacterial isolates}

Out of thethirty-six non-duplicated methicillin resistant staphylococci (MRS) collected from clini- cal specimens, thirteen were $S$. aureus and twentythree were coagulase negative staphylococci (CNS). Of these MRS isolates $27.8 \%$ were recovered from outpatients. Twenty-five percent came from patient suites, $14 \%$ from the ICU, $11 \%$ from the NICU, 11 $\%$ from the operating theater, $5.6 \%$ from the children's wing, and $5.6 \%$ from the recovery room. Sources of the MRS isolates were pus/tissue $(n=6)$, wound swabs $(n=9)$, blood $(n=11)$, respiratory tract $(n=4)$, urine $(n=2)$, and miscellaneous specimens ( $n$ $=4)$. The majority of the MRS isolates were isolated from males (56\%) and in the age group $\geq 40$ years (67\%) (Tables: 1a and 1b).

\section{Antimicrobial susceptibility}

The disk-diffusion agar technique identified all 36 staphylococcal isolates as methicillin resistant. All $36(100 \%)$ bacterial isolates were resistant to oxacillin, ampicillin, penicillin, augmentin, and cefalotin. However, all (100\%) were sensitive to vancomycin and teicoplanin. The percentage of methicillin-resistant coagulase-negative staphylococci (MRCNS)

Table 1a. Clinical data and sources of MRSA isolates

\begin{tabular}{|c|c|c|c|c|c|}
\hline Sample \# & Clinical Ward & $\begin{array}{c}\text { Date of } \\
\text { Isolation }\end{array}$ & Source & $\begin{array}{c}\text { Nature of } \\
\text { Specimen }\end{array}$ & $\begin{array}{c}\text { Sex/Age of } \\
\text { Patient (years) }\end{array}$ \\
\hline 2 & Outpatient & $20 / 9 / 10$ & Abdomen & Wound Swab & F/16 \\
\hline 3 & Patient suites & $28 / 9 / 10$ & Venous & Blood & M/72 \\
\hline 4 & Outpatient & $7 / 10 / 10$ & NA & Urine & F/56 \\
\hline 5 & Outpatient & $16 / 10 / 10$ & Venous & Blood & NA \\
\hline 7 & Patient suites & $20 / 1 / 11$ & Placenta & Tissue & F/62 \\
\hline 10 & Patient suites & $20 / 2 / 11$ & Respiratory Tract & Sputum & M/45 \\
\hline 20 & Patient suites & $6 / 3 / 11$ & Throat & Swab & M/22 \\
\hline 23 & Outpatient & $6 / 6 / 11$ & Arm & Wound Swab & F/59 \\
\hline 27 & Operating Theater & $21 / 6 / 11$ & NA & Bone & M/44 \\
\hline 28 & Patient suites & $30 / 6 / 11$ & NA & Wound Swab & M/46 \\
\hline 29 & Outpatient & $27 / 7 / 11$ & Leg & Wound Swab & F/28 \\
\hline & Outpatient & $29 / 7 / 11$ & Back & Wound Swab & M/73 \\
\hline
\end{tabular}

*MRSA: methicillin resistant $S$. aureus, NA: not available, M: male, F: female 
Table 1b. Clinical data and sources of MRCNS isolates

\begin{tabular}{|c|c|c|c|c|c|}
\hline Sample \# & Clinical Ward & $\begin{array}{l}\text { Date of } \\
\text { Isolation }\end{array}$ & Source & $\begin{array}{l}\text { Nature of } \\
\text { Specimen }\end{array}$ & $\begin{array}{c}\text { Sex/Age of } \\
\text { Patient (years) }\end{array}$ \\
\hline 1 & Outpatient & $10 / 9 / 10$ & NA & Urine & $\mathrm{M} / 97$ \\
\hline 8 & Children's Wing & $17 / 2 / 11$ & Venous & Blood & M/3 months \\
\hline 9 & Outpatient & $28 / 2 / 11$ & Leg & Wound Swab & $\mathrm{M} / 50$ \\
\hline 11 & ICU & $9 / 3 / 11$ & Venous & Blood & $\mathrm{M} / 82$ \\
\hline 12 & $\mathrm{ICU}$ & $15 / 3 / 11$ & Venous & Blood & $F / 81$ \\
\hline 13 & ICU & $22 / 3 / 11$ & Respiratory Tract & Sputum & $\mathrm{M} / 57$ \\
\hline 14 & Outpatient & $22 / 3 / 11$ & Skin Ulcer & Blood & F/53 \\
\hline 15 & Patient suites & $10 / 4 / 11$ & Venous & Pus & $\mathrm{M} / 77$ \\
\hline 16 & Patient suites & $11 / 4 / 11$ & Venous & Blood & F/38 \\
\hline 17 & $\mathrm{NICU}$ & $13 / 4 / 11$ & Lungs & Blood & M/1 day \\
\hline 18 & $\mathrm{NICU}$ & $2 / 6 / 11$ & Venous & DTA & $\mathrm{M} / 0$ \\
\hline 19 & Operating Theater & $3 / 6 / 11$ & Left hip & Blood & $\mathrm{F} / 60$ \\
\hline 21 & Outpatient & $9 / 6 / 11$ & Neck & Tissue & $F / 55$ \\
\hline 22 & NICU & $13 / 6 / 11$ & Left Eye & Wound Swab & $\mathrm{M} / 2$ days \\
\hline 24 & Patient suites & 23/6/11 & NA & Exudates & $\mathrm{M} / 74$ \\
\hline 25 & Patient suites & 27/6/11 & NA & Tissue & $\mathrm{M} / 76$ \\
\hline 30 & NICU & $4 / 9 / 11$ & NA & Catheter & M/1 day \\
\hline 31 & Operating Theater & $8 / 9 / 11$ & NA & Tissue & $\mathrm{F} / 42$ \\
\hline 32 & Recovery Room & $6 / 9 / 11$ & Left Thigh & Wound Swab & $\mathrm{F} / 79$ \\
\hline 33 & Operating Theater & $8 / 9 / 11$ & NA & Catheter & $F / 42$ \\
\hline 34 & $\mathrm{ICU}$ & $10 / 9 / 11$ & Venous & Blood & $\mathrm{M} / 80$ \\
\hline 35 & $\mathrm{ICU}$ & $14 / 9 / 11$ & Venous & Blood & F/69 \\
\hline 36 & Children's Wing & $17 / 9 / 11$ & Venous & Blood & $\mathrm{M} / 1$ month \\
\hline
\end{tabular}

* MRCNS: methicillin resistant coagulase-negative staphylococci, NA: not available, M: male, F: female, ICU: intensive care unit, NICU: neonatal intensive care unit, DTA: deep tracheal aspirate

which were resistant to clindamycin and erythromycin were $65 \%$ and $91 \%$ respectively; whereas, the percentage of methicillin-resistant S. aureus (MRSA) which were resistant to clindamycin and erythromycin were $31 \%$ and $38 \%$ respectively.

\section{SCCmec typing}

The SCCmec typing M-PCR1 assay included specific primers for the various SCCmec types, as well as an internal control primer for the detection of the mecA gene. This single M-PCR assay determined SCCmec types and subtypes I, II, III, IVa, IVb, IVc, $\mathrm{IVd}$, and $\mathrm{V}$ with the simultaneous discrimination between MRS and methicillin sensitive staphylococci (MSS) isolates (Figure 1).

M-PCR1 showed that 35/36 (97.2\%) of the MRS isolates were positive for the mecA gene confirming methicillin resistance. Isolate 1 was negative for 


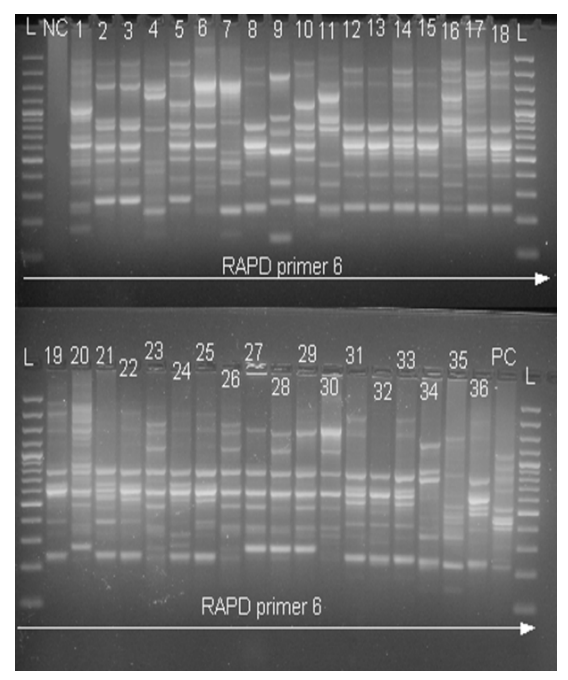

Figure 1. Gel electrophoresis of the M-PCR assay for the characterization of the SCCmectypes in MRS isolates. Lane 1 of the upper and lower gels represents the molecular weight marker (L: 50 bp ladder); lane 2 of the upper and lower gels represents the negative control (NC)

the mecA gene; however, it was phenotypically regarded as a methicillin resistant strain by the diskdiffusion agar method.

SCCmec typing also allowed for further typing and sub-typing of the MRS isolates, revealing the following: eighteen MRS isolates (51\%) contained SCCmec type IVa (776 bp), ten MRS isolates (29\%) contained SCCmec type III (280 bp), five MRS isolates (14\%) contained SCCmec type II (398 bp), one MRS isolate (3\%) contained SCCmec type IVc (200 bp), and one MRS isolate (3\%) contained SCCmec type I (613 bp). No SCCmec type $\mathrm{V}$ isolates was detected.

\section{MRSA-PVL PCR}

A total of 13 cultured MRSA isolates were subjected to MRSA-PVL PCR and none were PVL gene positive.

\section{Real Time semi-quantitative qRT- PCR}

Assay for detecting the gene encoding for the TSST-1 virulence factor showed that 2/13 MRSA isolates (isolates 2 and 3) were positive for the tst gene.

\section{Random amplified polymorphic DNA analysis (RAPD)}

In order to determine the genetic relatedness of these MRS strains, genotyping was done using Random Amplified Polymorphic DNA (RAPD) analysis. RAPD revealed 8 distinct clusters. These types were designated type $A, B, C, D, E, F, G$, and $H$; each with a prevalence of $8 \%, 17 \%, 25 \%, 14 \%, 19 \%, 3 \%$, $11 \%$, and $3 \%$ respectively.

The predominant RAPD type C included 9 methicillin resistant coagulase-negative staphylococci (MRCNS) isolates, having 58.5\% genomic similarity; five of them were CA and four were HA strains. All of these isolates were resistant to erythromycin, and all except three were resistant to clindamycin. Moreover, all were sensitive to the glycopeptides class of antimicrobial agents (vancomycin and teicoplanin). Isolates 12,13 and 15 of RAPD type C were genetically identical, all three containing SCCmec type IVa, indicating that they are community acquired strains. Isolates 12 and 13 were derived from the ICU and isolate 15 from patients' suites.

The RAPD type $E$ included 7 MRS isolates (6 MRSA and 1MRCNS), having $65.1 \%$ genomic similarity; four were HA and three were CA strains. These isolates were all susceptible to the glycopeptides. All but three were sensitive to erythromycin, and only two strains were resistant to clindamycin.

The RAPD type B included 6 MRCNS isolates, having 55\% genomic similarity; three were HA and three were CA strains. The vast majority of these isolates were resistant to clindamycin and erythromycin except for one isolate which was sensitive to both. All were susceptible to the glycopeptides. Isolates 21 and 22 of RAPD type B were genetically identical. Both were hospital acquired strains having SCCmec type II. Isolate 21 was isolated from an outpatient while isolate 22 was isolated from the NICU.

The RAPD type D included 5 methicillin resistant S. aureus (MRSA) isolates, having $55.3 \%$ genomic similarity; four were CA and one was a HA strain. These isolates were all sensitive to clindamycin, 
erythromycin, and the glycopeptides. Isolates 2 and 3 of RAPD type $D$ were genetically identical containing SCCmec type IVa; and hence, were CA strains. Isolate 2 was isolated from an out-patient whereas isolate 3 was isolated from patients' suites. These 2 MRSA isolates were positive for the TSST-1 toxin gene.

The RAPD type $G$ included 4 MRS isolates (2 MRSA and 2 MRCNS), having 30.2\% genomic similarity; three were HA and one was a CA strain. These isolates were all susceptible to the glycopeptides; however, they were resistant to erythromycin. All but one isolate were resistant to clindamycin.

The RAPD type A included 3 MRCNS isolates, having $45.6 \%$ genomic similarity; two were $C A$ and 1 was a HA strain. All three isolates were resistant to erythromycin and sensitive to glycopeptides, and one was sensitive to clindamycin.

The RAPD type $\mathrm{H}$ included only 1 MRCNS isolate. This isolate was HA, for it contained SCCmec type III. It was resistant to clindamycin and erythromycin and sensitive to the glycopeptides.

The RAPD type $\mathrm{F}$ also included only 1 MRCNS isolate which did not demonstrate the presence of the mecA gene; it was only phenotypically regarded as a methicillin resistant strain. This isolate was sen-

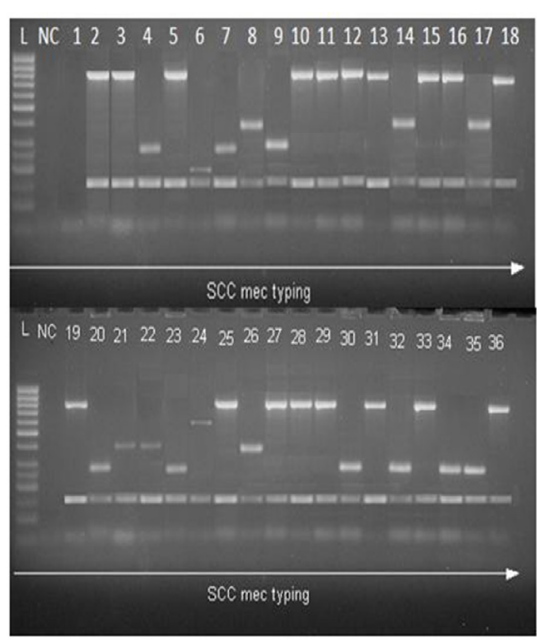

Figure 2. RAPD gel analysis for the MRS isolates; NC: negative control; L: molecular weight marker (100 bp ladder). sitive to clindamycin, erythromycin, and glycopeptides (Figures 2 \& $\mathbf{3}$ ).

\section{Discussion}

This study highlighted the antimicrobial-resistance profiles of the collected MRS isolates, which can serve as a useful reference for assessing the antibiotic resistant trends of the MRS strains in Lebanon.

Antimicrobial susceptibility testing showed that MRCNS are inclined to be more multi-drug resistant

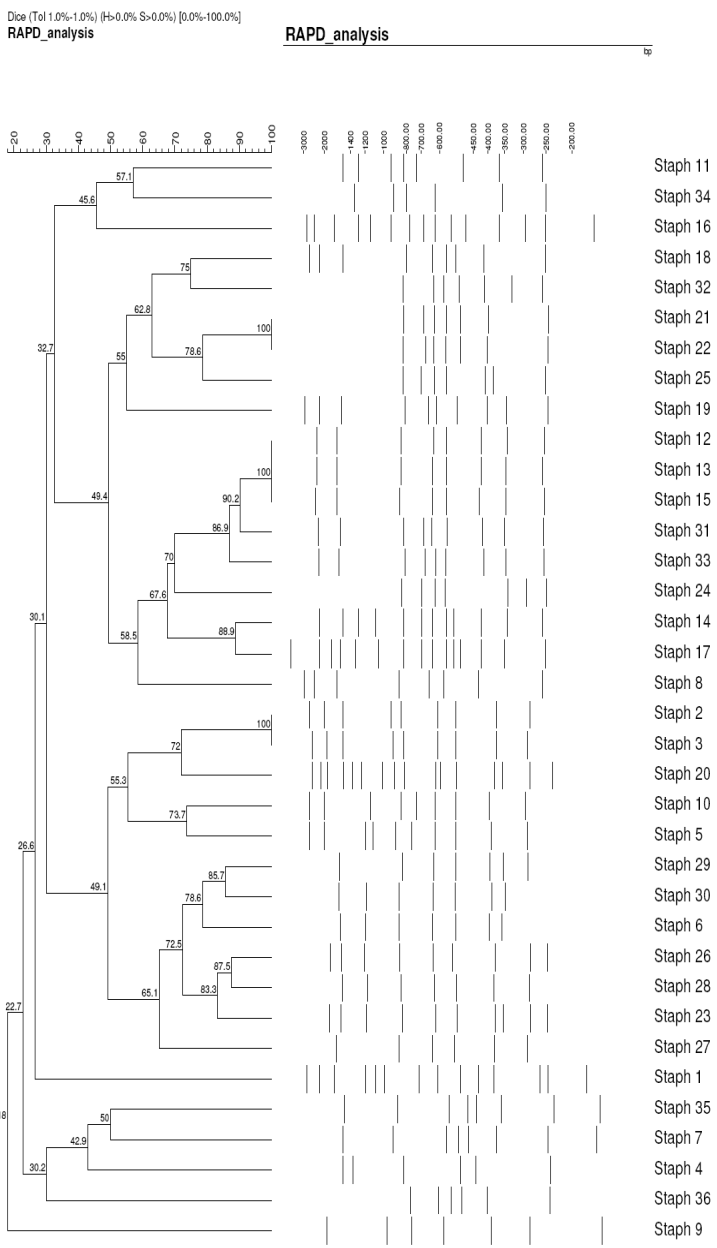

Figure 3. Dendrogram obtained from RAPD analysis, depicting clonal relationship (eight clusters: A, B, C, D, E, $F, G, \& H$ ) of the 36 MRS clinical isolates obtained from a Medical Center, Lebanon. 
Table 2. Characteristics of MRS isolates

\begin{tabular}{|c|c|c|c|c|}
\hline Isolate \# & Species & $\begin{array}{c}\text { Antibiotic } \\
\text { Susceptibility Type }\end{array}$ & SCC mec type & RAPD type \\
\hline 1 & CNS & 1 & N/A & $\mathrm{F}$ \\
\hline 2 & S.aureus & 1 & IVa & $\mathrm{D}$ \\
\hline 3 & S.aureus & 1 & IVa & $\mathrm{D}$ \\
\hline 4 & S.aureus & 2 & III & G \\
\hline 5 & S.aureus & 1 & IVa & $\mathrm{D}$ \\
\hline 6 & S.aureus & 1 & IVc & E \\
\hline 7 & S.aureus & 2 & III & G \\
\hline 8 & CNS & 2 & $\|$ & C \\
\hline 9 & CNS & 2 & III & $\mathrm{H}$ \\
\hline 10 & S.aureus & 1 & IVa & $D$ \\
\hline 11 & CNS & 3 & IVa & A \\
\hline 12 & CNS & 2 & IVa & C \\
\hline 13 & CNS & 2 & IVa & C \\
\hline 14 & CNS & 2 & $\|$ & C \\
\hline 15 & CNS & 2 & IVa & C \\
\hline 16 & CNS & 2 & IVa & A \\
\hline 17 & CNS & 3 & ॥ & C \\
\hline 18 & CNS & 2 & $\mathrm{IVa}$ & B \\
\hline 19 & CNS & 1 & IVa & B \\
\hline 20 & S.aureus & 1 & III & D \\
\hline 21 & CNS & 2 & ॥ & B \\
\hline 22 & CNS & 2 & ॥ & B \\
\hline 23 & S.aureus & 2 & III & E \\
\hline 24 & CNS & 2 & I & C \\
\hline 25 & CNS & 2 & IVa & B \\
\hline 26 & S.aureus & 3 & III & E \\
\hline 27 & S.aureus & 1 & IVa & E \\
\hline 28 & S.aureus & 1 & IVa & E \\
\hline 29 & S.aureus & 1 & IVa & E \\
\hline 30 & CNS & 2 & III & $\mathrm{E}$ \\
\hline 31 & CNS & 3 & IVa & C \\
\hline 32 & CNS & 2 & III & B \\
\hline 33 & CNS & 3 & IVa & C \\
\hline 34 & CNS & 2 & III & A \\
\hline 35 & CNS & 2 & III & G \\
\hline 36 & CNS & 3 & IVa & $\mathrm{G}$ \\
\hline
\end{tabular}

*CNS: coagulase-negative staphylococci, N/A: non-available 
than MRSA. Similar results have been documented in several studies [21]. The percentage of resistance to erythromycin and clindamycin in MRCNS isolates in this study was $91 \%$ and $65 \%$ respectively; whereas, the percentage of resistance to erythromycin and clindamycin in MRSA isolates was 38\% and $31 \%$ respectively. The high resistance rates to erythromycin and clindamycin renders the use of these antimicrobial agents inefficient in the treatment of MRS infections. Currently, the glycopeptides (vancomycin and teicoplanin) are considered the drugs of last resort against MRS infections; however, the emergence of vancomycin-intermediate and resistant staphylococcal strains has imposed a serious threat [22]. Moreover, all of the Staphylococcus isolates in this study were sensitive to vancomycin and teicoplanin.

Molecular characterization of the studied MRSA isolates by performing staphylococcal cassette chromosome mec (SCCmec) typing using M-PCR revealed that $53.8 \%$ of these MRSA isolates were SCCmec type IVa, 38.5\% were SCCmec type III and 7.7\% were SCCmec type IVc.

None of the MRSA isolates were pvl positive, but $15.4 \%$ of MRSA isolates were tst positive by qRTPCR. The presence of the tst gene, encoding for TSST-1, in isolates 2 and 3 is alarming because it can contribute to the invasiveness and severity of the $S$. aureus infection. Therefore, routine investigation for genes encoding virulence factors is recommended in order to predict potential diseases that may be associated with these virulence factors. This may lead to the application of the appropriate measures if possible to manage such diseases.

Furthermore, SCCmec typing by M-PCR allowed for the differentiation between HA-MRSA and CAMRSA[23]. Established molecular criteria classified isolates of MRSA harboring SCCmec type I-III as HA-MRSA and those harboring SCCmec type IV-V as CA-MRSA. The majority $(61.5 \%)$ of the collected MRSA isolates were CA. The existence of these isolates carrying SCCmec type IV in the hospital indicates the presence of a community reservoir or possibly the entrance of these isolates into the hospital environment; hence, CA-MRSA isolates are no longer confined to the community [24-26]. This change in the epidemiology of CA-MRSA has raised speculations concerning the origin of $C A$ and $H A$ MRSA. The basic structure of the SCCmec genetic element can provide an insight about the origin of CA and HA-MRSA. As noted earlier, the various SCCmec types share some basic structural features, including direct repeats, the ccr gene complex and the mec gene complex. The structural differences between the community-associated SCCmec types IV-V and the hospital-associated SCCmec types I-III rely mainly on the larger size and the presence of additional resistance determinants associated with HA-MRSA strains. Therefore, a possible explanation is that CA-MRSA has entered the hospital setting, acquired additional fragments and resistance determinants rendering them $\mathrm{HA}$.

CA-MRSA isolates have been known to be susceptible to non-beta-lactam antimicrobial agents. The antimicrobial susceptibility results obtained in this study confirm it; while $80 \%$ of HA-MRSA isolates showed multidrug-resistant phenotypes, all CA-MRSA isolates presented with a multi-drug susceptible pattern. Even though the CA-MRSA isolates were susceptible to multiple classes of antimicrobial agents as compared to HA-MRSA, 54\% of the patients were hospitalized, indicating the severity of infections caused by CA-MRSA.

SCCmec typing and RAPD analysis revealed that the staphylococcal isolates 2 and 3 which were characterized as CA-MRSA belonging to cluster D, isolates 12, 13 and 15 which were characterized as MRCNS carrying SCCmec type IVa belonging to cluster $C$, and isolates 21 and 22 which were characterized as MRCNS carrying SCCmec type ॥ belonging to cluster $B$, were genomically identical, and they were isolated within the same time period, hence, indicating possible outbreak strains[27].

The SCCmec genetic elements were highly preva- 
lent among MRCNS in this study. Moreover, there were strains of MRCNS and MRSA that showed close or possible genomic relatedness by RAPD (isolates $29 \& 30$ and isolates $7 \& 35$ showed $85.7 \%$ and $50 \%$ genomic similarity respectively). This indicates that MRCNS constitute potential reservoirs of the SCCmec that provide $S$. aureus with antimicrobialresistant determinants [28-32].

RAPD analysis revealed the presence of multiple SCCmec types within a single RAPD cluster. This indicates that staphylococcal clones having similar genomes may have developed methicillin-resistance upon the acquisition of the SCCmec genetic element by methicillin-sensitive strains of staphylococci.

The MRS isolates were diversified as defined by RAPD analysis, and there was a significant genomic heterogeneity particularly among staphylococcal isolates carrying the SCCmec type IV, which clustered into six RAPD types. This observation points out to the enhanced ability of SCCmec type IV genetic element to become mobilized, which is followed by its insertion into the chromosome of Staphylococcus species. Further, SCCmec types I, II and III were more commonly associated with $\mathrm{HA}$ isolates, whereas types IVa and IVc were more commonly associated with CA isolates.The small size associated with SCCmec type IV might aid in the transfer of this element on a plasmid or bacteriophage and hence, contributing to the enhanced spread of methicillin-resistance [33].

\section{References}

1. File TM. Methicillin-resistant Staphylococcus aureus (MRSA): focus on community-associated MRSA. South Afri J Epidemiol Infect 2008; 23: 13-15

2. Katayama Y, Ito T, Hiramatsu K. A New Class of Genetic Element, StaphylococcusCassette Chromosome mec, Encodes Methicillin Resistance in Staphylococcus aureus. Antimicrob Agents Chemoth 2000; 01;44(6):1549-1555.

3. Tokajian S. New epidemiology of Staphylococcus aureus infections in the Middle East. Clin Microbiol Infect 2014; 20(7):624-628
4. Shehabi AA, Abu-Yousef R, Badran E, Al-Bakri AG, AbuQatouseh LF, Becker K. Major Characteristics of Staphylococcus aureus colonizing Jordanian infants. Pediatr Int. 2013; 55(3):300304.

5. Nazeer A, Al-Tawfiq JA. Methicillin-resistant Staphylococcus aureus metrics for patients in Saudi Arabia. J Infect Dev Ctries 2012;6(3):223-233.

6. Ito T, Ma XX, Takeuchi F, Okuma K, Yuzawa H, Hiramatsu K. Novel type $V$ staphylococcal cassette chromosome mec driven by a novel cassette chromosome recombinase, ccrC. Antimicrob Agents Chemother 2004 Jul;48(7):2637-2651.

7. Boyle-Vavra S, Ereshefsky B, Wang CC, Daum RS, et al. Successful multiresistantcommunity-associated methicillinresistant Staphylococcus aureus lineage fromTaipei, Taiwan, that carries either the novel Staphylococcal chromosome cassette mec (SCCmec) type VT or SCCmec type IV. J Clin Microbiol 2005; 43:4719-4730.

8. Ito T, Katayama Y, Hiramatsu K. Cloning and Nucleotide Sequence Determinationof the Entire mec DNA of PreMethicillin-Resistant Staphylococcus aureus N315.Antimicrob Agents Chemother 1999; 43(6):1449-1458.

9. Deresinski S. Methicillin-resistant Staphylococcus aureus: an evolutionary,epidemiologic, and therapeutic odyssey. Clin Infect Dis 2005, 15;40(4):562-573.

10. International Working Group on the Classification of Staphylococcal CassetteChromosome Elements (IWG-SCC). Classification of Staphylococcal CassetteChromosome mec (SCCmec): Guidelines for Reporting Novel SCCmec Elements. Antimicrob Agents Chemother 2009; 53(12):4961- 4967.

11. Prevost G, Mourey L, Colin DA, Menestrina G, et al. Staphylococcal pore-formingtoxins. Curr Top Microbiol Immunol 2001;257:53-83

12. Bohach GA, FastDJ, Nelson RD, Schlievert PM. Staphylococcal and streptococcalpyrogenic toxins involved in toxic shock syndrome and related illnesses. Crit RevMicrobiol 1990;17(4):251-272.

13. Zhang K, McClure JA, Elsayed S, Louie T, Conly JM. Novel multiplex PCR assay for characterization and concomitant subtyping of staphylococcal cassette chromosome mec types I to $V$ in methicillin-resistant Staphylococcus aureus. J Clin Microbiol 2005;43(10):5026-5033.

14. Dana A. Bazzoun, Houda H. Harastani, Asem A. Shehabi, Sima T. Tokajian. Molecular typing of Staphylococcus aureus collected from a Major Hospital in Amman, Jordan. J Infect Dev Ctries 2014; 8(4):441-447.

15. Harastani HH, Araj GF, Tokajian ST. Molecular characteristics of Staphylococcus aureus isolated from a major hospital in Lebanon. Int Infect Dis 2014;19(1):33-38.

16. Harastani HH, Tokajian ST. Community-associated methicillinresistant Staphylococcus aureus clonal complex 80 type IV (CC80-MRSA-IV) isolated from the Middle East: A heterogeneous expanding clonal lineage. PLOS ONE 2014;9(7).

17. Sfeir M, Obeid Y, Eid C, Saliby M, Farra A, Farhat H, et al. Prevalence of Staphylococcus aureus methicillin-sensitive and methicillinresistant nasal and pharyngeal colonization in outpatients in Lebanon. Am J Infect Control 2014:42(2):160-163. 
18. Tokajian S. Newepidemiology of Staphylococcus aureus infections in the Middle East. Clin Microbiol Infect 2014;20(7):624-628.

19. Tokajian ST, Khalil PA, Jabbour D, Rizk M, Farah MJ, Hashwa FA, et al. Molecular characterization of Staphylococcus aureus in Lebanon. Epidemiol Infect 2010;138(5):707-712

20. Clinical and Laboratory Standards Institute. CLSI Guidlines. January 2011.

21. Higuchi W, Isobe H, Iwao Y, Dohmae S, Saito K, Takano T, et al. Extensive multidrug resistance of coagulase-negative staphylococci in medical students. J Infect Chemother 2007 Feb;13(1):63-66.

22. Tomoda H. Mode of action of microbial anti-MRSA agents. Yakugaku Zasshi 2012; 132(1):37-44.

23. Moroney SM, Heller LC, Arbuckle J, Talavera M, Widen $\mathrm{RH}$. Staphylococcalcassette chromosome mec and PantonValentine leukocidin characterization ofmethicillin-resistant Staphylococcus aureus clones. J Clin Microbiol 2007;45(3):10191021.

24. de Trindade A, Pacheco RL, Costa SF, Rossi F, Barone AA, Mamizuka EM, et al.Prevalence of SCCmec type IV in nosocomial bloodstream isolates of methicillinresistant Staphylococcus aureus. J Clin Microbiol 2005:43, 3435-3437.

25. Kilic A, Li H, Stratton CW, Tang YW. Antimicrobial susceptibility patterns andstaphylococcal cassette chromosome mec types of, as well as Panton-Valentineleukocidin occurrence among, methicillin-resistant Staphylococcus aureus isolates from children and adults in middle Tennessee. J Clin Microbiol 2006:44, 44364440.

26. Seybold U, Kourbatova EV, Johnson JG, Halvosa SJ, Wang YF, King MD, et al.Emergence of community-associated methicillinresistant Staphylococcus aureusUSA300 genotype as a major cause of health care-associated blood stream infections.Clin Infect Dis 2006:42, 647-656.

27. Tenover FC, Arbeit RD, Goering RV, Mickelsen PA, Murray BE, Persing $\mathrm{DH}$, et al.Interpreting chromosomal DNA restriction patterns produced by pulsed-field gelelectrophoresis: criteria for bacterial strain typing. J Clin Microbiol 1995;33(9):2233-2239.

28. Couto I, Sanches IS, Sa-Leao R, de Lencastre H, et al. Molecular characterization ofStaphylococcus sciuri strains isolated from humans. J Clin Microbiol 2000;38: 1136-1143.

29. Couto I, de Lencastre $H$, Severina $E$, Kloos W, Webster JA, Hubner RJ, et al.Ubiquitous presence of a mecA homologue in natural isolates of Staphylococcussciuri. Microb Drug Resist 1996; 2(4):377-391

30. Archer GL, Thanassi JA, Niemeyer DM, Pucci MJ, et al. Characterization ofIS1272, an insertion sequence-like element from Staphylococcus haemolyticus.Antimicrob Agents Chemother 1996;40: 924-929.

31. Kobayashi N, Urasawa S, Uehara N, Watanabe N. Distribution of insertionsequence-like element IS1272 and its position relative to methicillin resistance genesin clinically important Staphylococci. Antimicrob Agents Chemother 1999Nov;43(11):2780-2782.

32. Wielders $C L$, Vriens $M R$, Brisse $S$, de Graaf-Miltenburg LA, Troelstra A, Fleer A,et al. In-vivo transfer of mecA DNA to Staphylococcus aureus [corrected. Lancet 2001; 26;357(9269):1674-1675.

33. Adhikari RP, Cook GM, Lamont I, Lang S, Heffernan H, Smith JM, et al. Phenotypic and molecular characterization of community occurring, Western Samoan phage pattern methicillin-resistant Staphylococcus aureus. J Antimicrob Chemother 2002;50:825831.

\section{Comment on this article:}

\section{8 in $8+S P$}

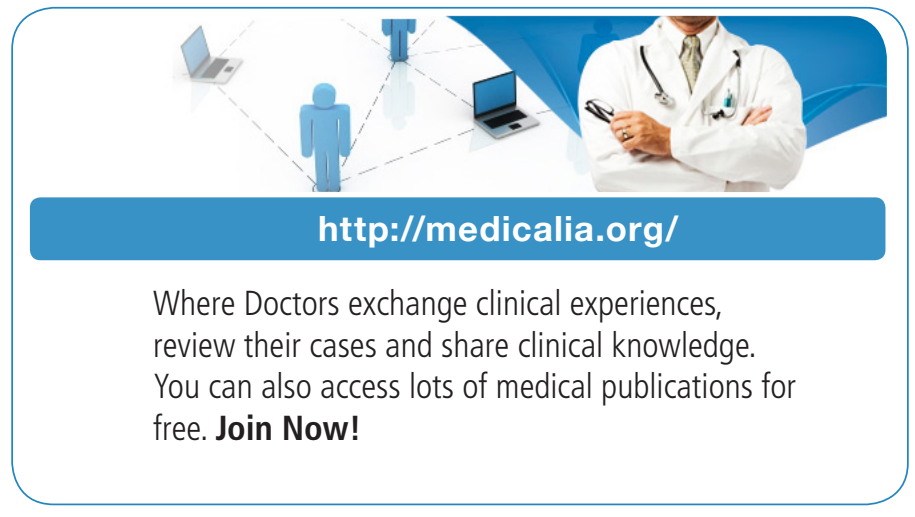

\section{Publish with iMedPub}

http://www.imed.pub

The Journal is an open access peer-reviewed journal that publishes scientific papers about all aspects of antimicrobials. The journal will publish original research articles, reviews, brief reports and case reports dealing with basic and clinical antibacterial agents, antiviral, antiprotozoals, antituberculuous, antifungal and antihelminthes agents.

All manuscripts must be prepared in English, and are subject to a rigorous and fair peer-review process. Accepted papers will immediately appear online.

The journal aims to advance the knowledge, attitude and the research of chemotherapy in the Arabic world in cooperation with international, national scientific and public societies as well as research centers with similar aims and objectives. 